\title{
UMA COLEÇÃO DE CASTANHEIRAS POSSÍVEIS
}

\author{
Cinthya Marques do Nascimento \\ Universidade Federal do Sul e Sudeste do Pará - UNIFESSPA
}

\begin{abstract}
Resumo
Partindo do conceito de coleção enquanto poética, o presente trabalho desafia discutir as possibilidades visuais em uma coleção que parte de imagens de árvores castanheiras, relacionando com obras de artistas que utilizam esta temática, em busca de refletir sobre a simbologia da castanheira enquanto memória coletiva da região em consonância com a coleção.
\end{abstract}

\section{Palavras-chave:}

Castanheiras; coleção; imagem.

\section{INTRODUÇÃO}

As árvores castanheiras, fixas e estáveis, são elementos visuais presentes nas paisagens do sul e sudeste do Pará. Elas habitam boa parte desta geografia e são símbolos de resistência, carregam consigo anos de exploração permanente desta região.

$\mathrm{Na}$ paisagem contemporânea essas árvores emergem nos campos amazônicos solitárias e isoladas, sendo que as castanheiras encontramse hoje em menor escala do que foram outrora - quando elas desempenharam papel fundante durante o ciclo da castanha, um dos principais ciclos de exploração da Amazônia. Nos dias atuais a castanheira aparece na lista de espécies ameaçadas do Ministério do Meio Ambiente. A principal causa para o risco de extinção é o desmatamento. No Brasil os castanhais são derrubados para a construção de estradas e barragens, para assentamentos de reforma agrária e para a criação de gado.

As castanheiras solitárias guardam consigo marcas dos incessantes períodos em que foram exterminadas. Refletir sobre a solidão dessas árvores é também buscar uma simbologia

\section{Abstract}

Starting from the concept of collection as poetics, the present work challenges to discuss the visual possibilities in a collection that starts from images of chestnut trees, relating with works of artists that use this theme, in search of reflecting on the chestnut tree symbology as a collective memory of the region in line with the collection.

Keywords:

Chestnut; collection; image.

enquanto memória coletiva e seus permanentes ciclos de exploração. Elas estão presentes enquanto símbolo da cidade de Marabá - principal cidade do sudeste paraense, e presentes nos campos abertos formados por pastagens cuja vegetação vem sendo modificada para favorecer a prática da pecuária nos solos da Amazônia.

Este artigo pretende refletir sobre 0 isolamento na paisagem das árvores castanheiras que se encontram nos campos do sudeste do estado do Pará, e suas relações enquanto memória coletiva da região, apresentando obras e objetos visuais de artistas que refletem sobre o mesmo tema. Esta pesquisa inicia-se após o encontro do ambiente favorável para observar as solitárias castanheiras, em que começo a guardar/colecionar essas imagens das árvores. Sabendo disso, coleciono árvores na minha memória. Por que não fotografá-las?

\section{RELAÇÃO COM O PROJETO URBANÍSTICO DA NOVA MARABÁ}

Em Marabá, uma das principais cidades dessa região, as castanheiras são o símbolo do projeto urbanístico do núcleo habitacional da cidade "Nova Marabá". Neste ambiente as "ruas" são setores chamados de "folhas", que se assemelham ao 


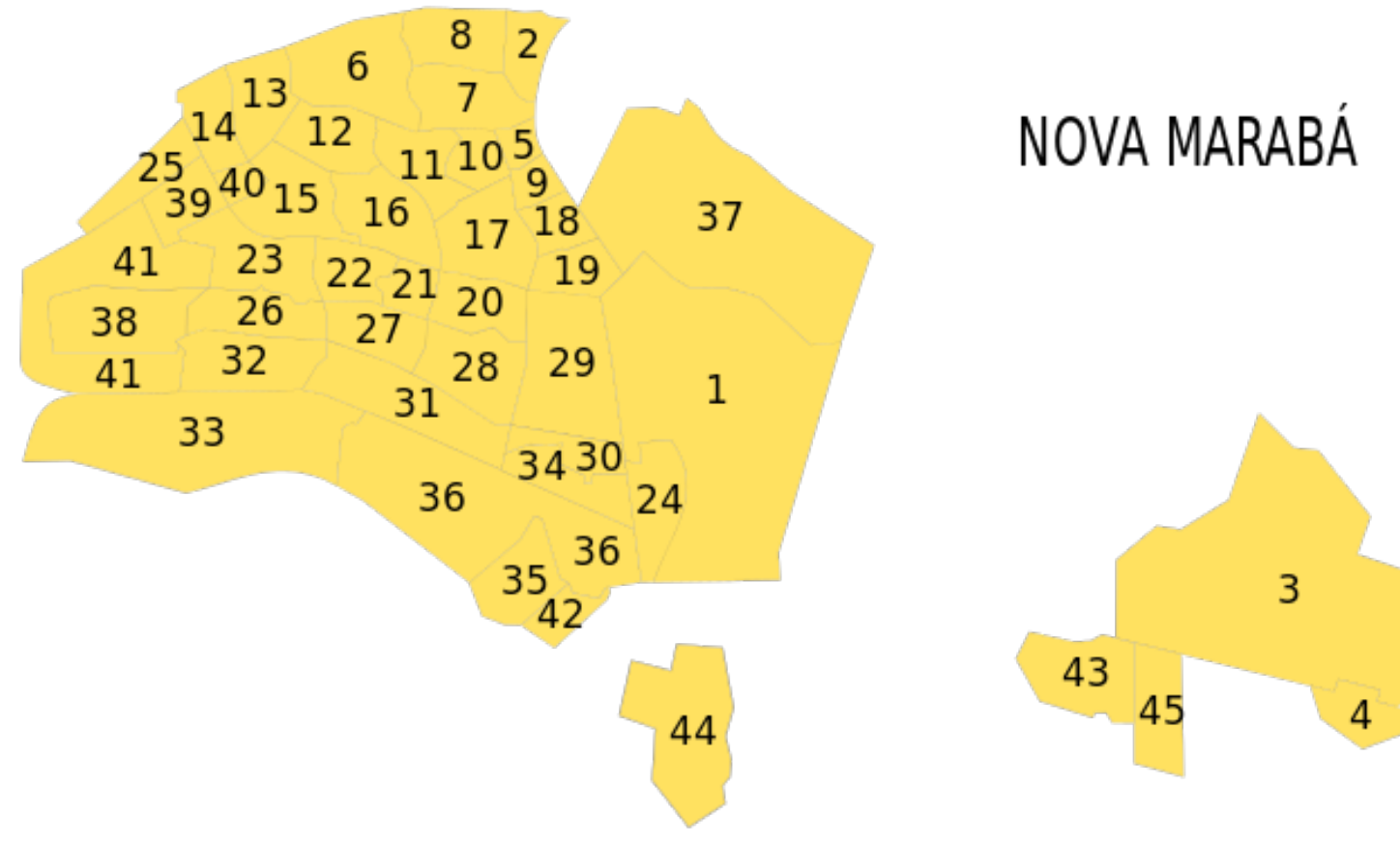

\section{NOVA MARABÁ}

Figura 1 - Mapa ubanístico da Nova Marabá. Fonte: https://pt.wikipedia.org/wiki/Lista_de_bairros_de_Marab\%C3\%A1

conceito de "bairros" por conta de sua extensão residencial e comercial - cada "folha" conta com serviços próprios, proporcionando aos moradores que não necessitem sair de uma folha para outra - excluindo-se hospitais, cartórios e rodoviárias, a maioria dos outros serviços são encontrados nas folhas habitacionais que fazem parte de uma castanheira imaginária, e que representa a grandiosidade dessa árvore.

Visualizando o mapa da Nova Marabá é possível perceber que este conceito não se aplica pois na prática as "folhas" são geométricas e setorizadas, então o conceito da "grande castanheira" tem mais relação com a projeção desta parte da cidade - e seu conjunto de vias e rotatórias, do que com o conceito inicial.

A criação deste núcleo visava atender o crescimento geográfico populacional que se consolidava com a migração de grupos vindo para ocupar a região amazônica - período que remete ao slogan da ditadura militar "Integrar para não entregar" - bem como afastar do contexto urbano as enchentes que caracterizam a região.

O núcleo fundador da cidade, conhecido como "Velha Marabá" ou "Marabá Pioneira", sofreu - atualmente ainda vive sob essa ameça anual durante o inverno amazônico - de enchentes que invadiam casas e destruiam a vida das populações que habitam as áreas alagadas, deixando-as desabrigadas nos períodos das grandes cheias. A citar a grande enchente de 1980 que é lembrada pelos habitantes como o dia em que o rio Tocantins subiu quase 18 metros - acontecimento que entrou para história da cidade, e que faria muitos habitantes abandonarem esta área da cidade em busca de melhores condições de vida.

Sendo assim, inicia-se uma ocupação desordenada no núcleo da Nova Marabá a partir de 1981 , e a população migra para esta parte da cidade que está acima do nível dos rios. Ao aproximar a estrutura da cidade a uma estrutura vegetal, que lembrava uma árvore, o criador do projeto urbanístico - Joaquim Guedes - previa que a expansão do núcleo urbano ocorresse de forma ordenada - fato que não ocorreu devido o abandono do projeto pela SUDAM via Governo Federal após a grande enchente de 1980.

\section{AS CASTANHEIRAS REFLETIDAS: MINHA EXPERIÊNCIA COMO ARTISTA-EDUCADORA}

Data de 2011 meu primeiro contato com a cidade de Marabá. Eu viria para esta região por acaso, quando ao final da graduaçao em Artes Visuais, surgiu o convite para desenvolver uma oficina de "Iniciação à Fotografia" para professores da rede 


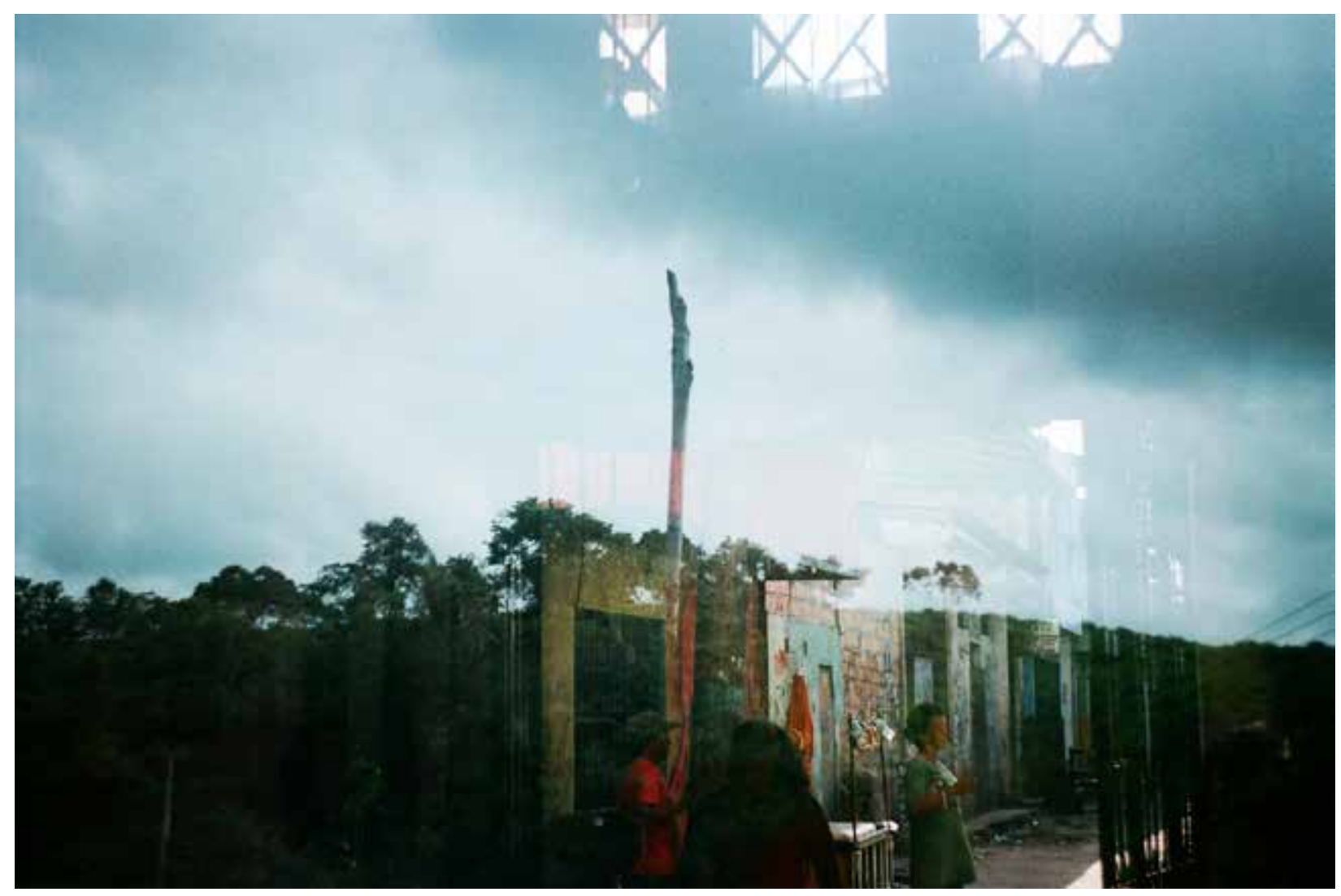

Figura 2 - Fragmento da série "Dois mundos à espera"1, Cinthya Marques. 2016, PA.

municipal de Canaã dos Carajás. Éramos um trio de arte-educadoras que durante um fim de semana viveram a experiência de conhecer uma realidade distante da capital do estado, e arriscaram vivenciar o ensino e aprendizagem artística com um grupo de educadores ansiosos por novas possibilidades educativas, que participaram de micro-oficinas: maquiagem artística, iniciação à fotografia e teatro.

Após um período de cinco anos com estas lembranças na memória, retorno pra região em 2016, quando passo a integrar a equipe de educadores de um projeto que visava desenvolver oficinas de educação patrimonial às comunidades atingidas pelas barragens da mineradora Vale, que explora a Serra dos Carajás, e exporta diariamente toneladas de minério de ferro para fora do Brasil. Essas comunidades estão inseridas no contexto de extrema pobreza, e foi então que eu percebi o quanto essas populações sofrem permanetemente com os reflexos da corrupção do congresso brasileiro e da exploração desenfreada dos recursos minerais e florestais da Amazônia.
Era nesse cenário que eu me encontrava e na época. Percorria longos períodos de estrada em deslocamento para os municípios, partindo diariamente da cidade de Parauapebas, localizada no sudeste do Pará, município que está assentado na maior província mineral do planeta, a Serra dos Carajás.

Mesmo contra meus princípios, aceitei o cargo pois sempre quis conhecer a região, e nesta vida de artista-pesquisadora eu tinha também algumas contas para pagar. Não me orgulho disto; mas tambem não posso passar por cima desse fragmento da minha história vivenciada. Sendo assim, então, aceitei o cargo de técnica em educação patrimonial para desenvolver práticas educativas em diálogo com a arte-educação - função desviada posteriormente quando me tornei uma espécie de fotógrafa responsável pelos registros das ações, haja vista que a coordenação do projeto conheceu minha experiência com a fotografia documental e o fotojornalismo.

Facilmente fui introduzida a esta categoria entre os membros da equipe Serra Norte - responsável 


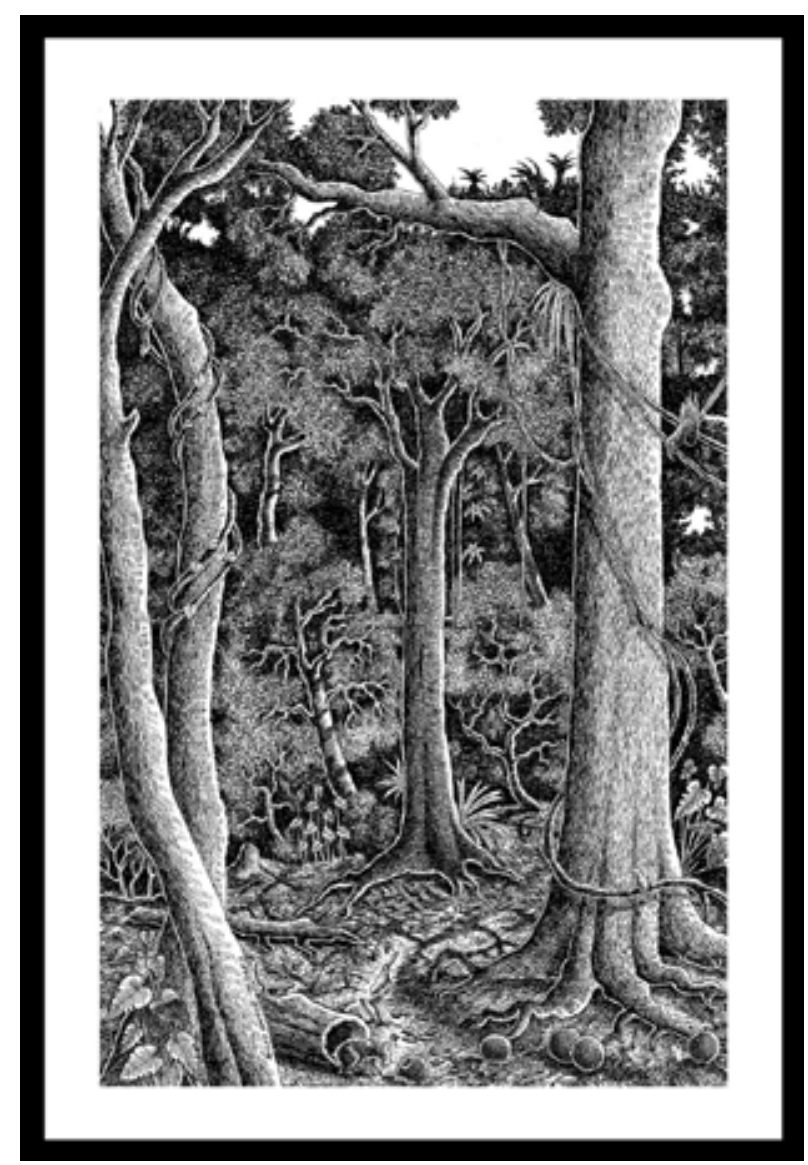

Figura 3 - Castanheiras, Rildo Brasil. PA. s/d

por realizar ações presenciais nas comunidades próximas a Serra de Carajás, são elas: Vila Sanção, Vila Paulo Fonteles, APA (Área de Proteção Ambiental), Palmares I e Palmares II. Essas regiões expressam a extrema pobreza e o total descaso com as suas populações. Em uma das vilas que passei maior tempo, a Vila Sanção, as crianças não sabiam usar o banheiro e muitas casas de moradores não tinham sequer cisterna própria. A comida, sempre muito simples, é baseada no consumo diário de carne bovina.

As fotografias de castanheiras foram feitas durante longas viagens por municípios localizados aos arredores da cidade de Parauapebas. Neste ambiente a paisagem é formada por fazendas do agronegócio, e o principal elemento visual presente nestas paisagens são os bois e os pastos. Longos campos de devastação.

Sendo assim, para aliviar o tédio entre idas e vindas de horas de viagens, comecei a catalogar visualmente essas castanheiras que observava durante os trajetos na estrada. As paisagens me provocavam: vastos campos desmatados e transformados em pastos, tomados por rebanhos de gados e um ponto nesta paisagem se destacava, eram essas árvores que resistiam, solitárias, atravessando o tempo. Comecei a criar afetividade por essas árvores grandiosas, imponentes e solitárias. Observando pela janela do carro comecei a fotografá-las.

\section{AS CASTANHEIRAS ENQUANTO VISUALIDADE}

As representações dos castanhais e das árvores castanheiras nas artes visuais estão presentes principalmente em obras de artistas da região Norte do Brasil, região onde se insere $80 \%$ da floresta amazônica. Artistas dessa região vem documentando olhares e pontos de vista sobre diversas temáticas que integram a paisagem desta região, tais como a fauna e flora, costumes e tradições locais, vivências e experiências da vida na Amazônia.

A imagem nunca é uma realidade simples ${ }^{2}$ afirma Jacques Rancière e, diante do exposto, irei apresentar a obras de artistas que representam a temática dos castanhais e castanheiras, visando contribuir com as realidades complexas que se apresentam, relacionando com a visualidade presente no imaginário local que busca dialogar com essas temáticas.

De fato, quando observamos as composições em nanquin dos artistas da região de Marabá percebemos que seus trabalhos são voltados para a documentação da região, através da utilização do bico de pena para composição de seus trabalhos.

Neste contexto são abordados temas como exploração dos castanhais, queimadas, condições de vida dos castanheiros nos barracões - que são explorados diretamente no seu redimento, a vida ribeirinha e indígena, a natureza, o povo, as conquistas da região e o sofrimento local. Estes artistas documentam ao mesmo tempo que denunciam o cotidiano de exploração que vive a região amazônica e as populações que inseridas neste cenário.

Rildo Brasil é artista de uma geração que é responsável pela disseminação da técnica na região, influenciado por Augusto e Pedro Morbach e o peruano Percy Lau que utilizam - se do nanquim para construir realidades múltiplas 


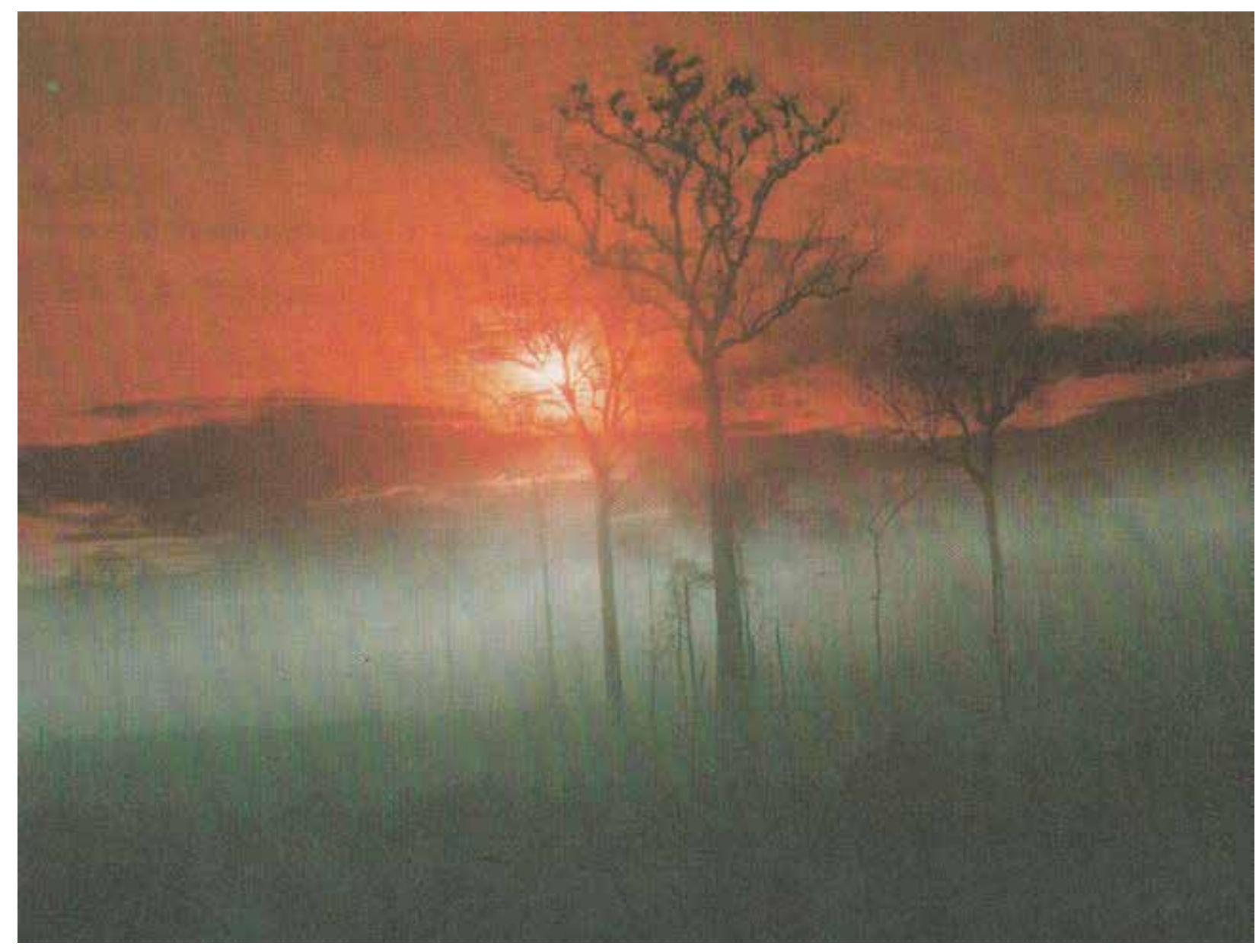

Figura 4 - Castanheiras mortas, de Jorge Macedo de Souza. Boa Vista, RR, 1985

próximas do contexto atual, mas que denunciam e constroem um retrato da realidade local pouco conhecida a nível nacional. Na obra Castanheiras o artista utiliza a técnica para detalhar a forma dessas árvores, as curvas de suas raízes, o entreleçamento existente entre elas na mata e a grandiosidade que carrega a sua existência na floresta amazônica.

Do mesmo modo, em busca de referências para a construção desse trabalho entrei em contato com o catálogo da primeira edição do Fotonorte (1987), iniciativa que reuniu em exposições e documentários visuais a produção dos fotógrafos que estão localizados fora do eixo Rio-São Paulo. $\mathrm{Na}$ época o projeto mapeava os fotógrafos da região Norte do Brasil que documentavam o cotidiano de cidades e estados poucos conhecidos do público em geral - fugindo do viés exótico, este lugar comum em que se colocou a região amazônica por muito tempo.
Uma imagem que sem dúvida me atravessou no processo dessa pesquisa foi Castanheiras mortas do fotógrafo Jorge Macedo de Souza, que registra uma cena com ares apocalípticos - seja pelo vermelho do céu ou pela penumbra que encobre as castanheiras mortas em Boa Vista, na capital de Roraima em 1985. A cena remete a um cenário de queimadas e destruição da fauna e flora amazônica para dar vazão ao desmatamento, que vemos refletido mais de 30 anos depois com o aumento das ondas de calor na região de clima tropical e o avanço do agronegócio, transformando mata em pasto de criação de gado.

Esses símbolos - as castanheiras queimadas e sua presença forte mesmo depois de morta retornam na instalação As Castanheiras de Eldorado dos Carajás (1999, 25mx8m) do artista visual e arte educador Dan Baron, que ao fixar residência na região constrói o monumento coletivamente com mais de 800 sobreviventes do massacre de Eldorado dos Carajás (17 de abril de 1996), no 


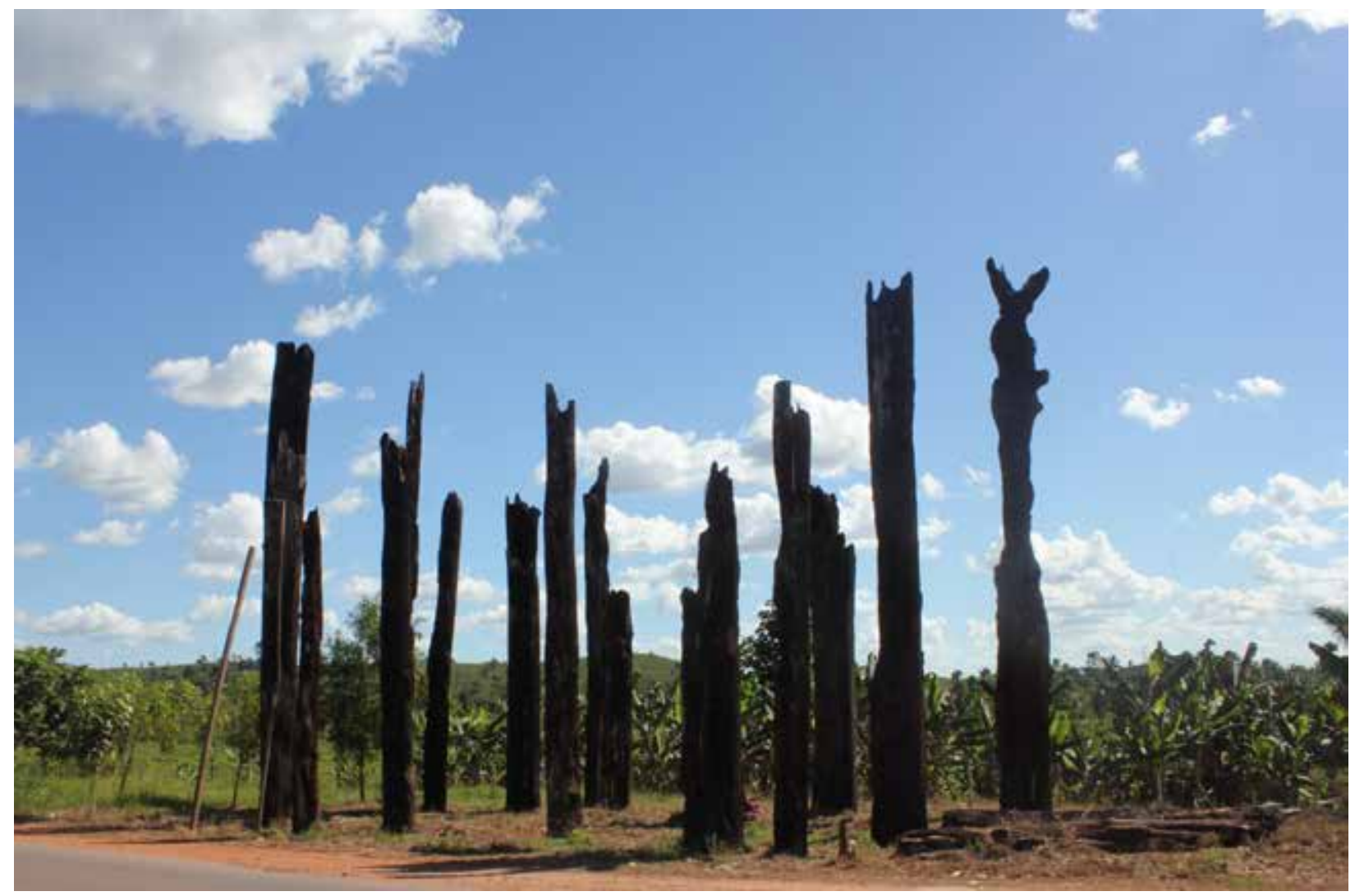

Figura 5 - As castanheiras de Eldorado dos Carajás, de Dan Baron e MST, PA, 1999.

sul do Pará, cenário dos crimes contra os povos amazônicos, e símbolo da luta pela terra e a natureza. O convite para realizar a obra partiu da direção estadual do MST-Pará.

\footnotetext{
"A escultura monumental é formada por dezenove árvoes de castanheira, queimadas e mutiladas pelos latifundiários, inspirada no uso dos corpos dos sobreviventes como objetos íntimos, com a proposta de 'codificar' o mundo objetivo que eles internalizaram (...) o monumento permite que a comunidade massacrada e todo o movimento SemTerra visualizem o relacionamento entre as vozes interna e extena da sua cultura de resistência." (BARON, Dan. Alfabetização Cultural - a luta íntima por uma nova humanidade. São Paulo, 2004, p. 241)

O massacre ficou conhecido internacionalmente como uma violenta ação da polícia do Pará contra famílias integrantes do Movimento Sem - Terra, que detém em sua história de luta a pauta da reforma agrária. Esses camponeses estavam acampados na região quando por ação do fazendeiro proprietário da área com a conivência do governador do estado à epoca, a polícia militar invadiu a área disparando contra os assentados que não detinham armas de fogo - lutavam com paus e pedras pela vida de seus filhos, amigos e familiares.
}

O massacre é anualmente lembrado na região conhecida como "curva do S" - local que aconteceu o ataque - e que recebe grupos de ativistas sociais anualmente na data de aniversário do massacre, em memória daqueles que trocaram sua vida pela esperança de ter seus direitos assegurados conforme rege a constituição.

Atuando de forma simbólica na região, a instalação reuniu todos em volta de uma construção coletiva, porém esta obra se recusa a ser monumento que idealiza, homenageia ou enfatiza uma lembrança, pois age na esfera das memórias dolorosas e cruéis que marcam o episódio, sendo sempre ponto de encontro para o renascimento de ideias que fortaleçam este fato histórico. Esta renovação é compartilhada com a plantação de novas mudas de castanheiras que são plantadas a fim de ocupar o lugar daquelas que vão desaparecendo com o tempo.

"A obra usa nosso mundo violentado para destacar uma crise muito mais perigosa: como nossa memória está sendo permanentemente roubada, fabricada e refabricada em imagens e museus a serviço do mercado (...) esta escultura coletiva se propõe como uma marca antineoliberal, um teatro 
periférico de resistência e libertação." (BARON, Dan. Alfabetização Cultural - a luta íntima por uma nova humanidade. São Paulo, 2004, p. 242)

Estes símbolos habitam a memória coletiva de quem convive com esta região e dos brasileiros que interpretam a história do ponto de vista histórico e social. Antes mesmo de discutir se iria ou não habitar esta região eu me impressionava com a grandiosidade da obra de Dan Baron. Ao descobrir que este monumento é um reflexo da memória coletiva dos integrantes do Movimento Sem - Terra entendo a importância da obra para a memória coletiva que se constroi no lugar.

Foram apresentados obras de artistas que em diálogo com a temática discutida aqui propõem refletir sobre a simbologia dessas árvores, vivas ou mortas, florescendo ou queimadas, fonte de alimento ou de sombra, solitárias ou acompanhadas, imponentes ou destruídas, as castanheiras estão agindo no campo simbólico que Rancière chama de Arquissemelhança que se traduz para o cotidiano como $A$ imagem da arte separa suas operação da técnica que produz semelhanças ${ }^{3}$, sendo assim as imagens apresentadas reencontram em seu caminho outra semelhante, e diante disto dispensa o espelho que reflete a si mesma, tornado-se o testemunho imediato do que se é, e do lugar em que se encontra.

Podemos considerar então, que estas imagens e projetos sempre estiveram, de algum modo na minha memória enquanto referências visuais na construção dos objetos que apresento neste trabalho, e que, se dispondo a ser referência transformam-se na apresentação de um lugar e um ponto de vista para a construção desse trabalho de uma coleção possível.

\section{AS POSSIBILIDADES DE UMA COLEÇÃO IMPOSSÍVEL}

Ao iniciar a documentação visual destas árvores passei a refletir sobre o isolamento das castanheiras na paisagem, que se assemelham em certa medida à minha própria solidão - esta solidão que se vive acompanhada, interagindo com desconhecidos, que desconhecem nossos sonhos, nossos desejos mais profundos, e até mesmo a nossa origem.

Por outro lado essas paisagens me provocavam, levando-me a questionar sobre as imensas áreas que foram desmatadas para se tornarem pastos, para abrigar rebanhos de gados e demais animais que proporcionam lucro aos fazendeiros. Constatava ali, diante dos meus olhos, o avanço do agronegócio que enriquece poucos e mantém muitos na miséria, sob condições de trabalho adversas, tais como as famílias sem-terra que foram massacradas na Curva do $\mathrm{S}$ em Eldorado dos Carajás, e que lidavam com as injustiças de ter seu direito a propriedade negada com a ausência de políticas públicas e da reforma agrária.

Diante de tantos questionamentos passo a cultivar certa afetividade por essas árvores grandiosas, que se descatam na paisagem, árvores imponentes e solitárias, que resistem através do tempo, que me fizeram refletir sobre a forma como eu me sentia diante dessas árvores, ao imaginar quantos dias de sol e chuva elas haviam vivido? Quantos madereiros com motosserras elas tinham conhecido? Quanta dor haviam sentido as suas raízes e troncos com o avanço dos pastos de criação de gado? Quantos frutos haviam sido negados? Sentimentos que foram construídos ao longo do projeto pela necessidade de humanizar essa realidade e desta solidão que se encontra nos campos do sudeste do estado do Pará, nas memórias coletivas construídas ao longo de anos de exploração da região.

A ação de colecionar surge como uma tentativa de proteger e imortalizar estas árvores castanheiras. Porém não cabe apenas colecioná-las em minha memória. Colecionar é guardar, proteger uma memória. Diante da impossibilidade de colecionar as castanheiras, resta fotografá-las. É possível colecionar o incolecionável?

No texto $O$ Colecionador presente na obra Passagens de Walter Benjamin, o autor afirma que o colecionador se assemelha com aquele que sonha e partilha de uma vida onírica, já que suas percepções modificam-se diante do objeto colecionável. Porém, diferente dos objetos das coleções estudadas por Benjamin, esta coleção de árvores castanheiras não são produtos do ambiente industrial - tal como os objetos que o autor analisa em seu texto. Para colecionar essas castanheiras foi preciso direcionar a atenção para o objeto colecionável em percursos pouco óbvios, alimentando esta coleção com as fotografias das castanheiras intocáveis nesta paisagem amazônica.

“Poder-sia dizer que, se vivêssemos segundo um outro ritmo - mais serenos diante de certas coisas, 

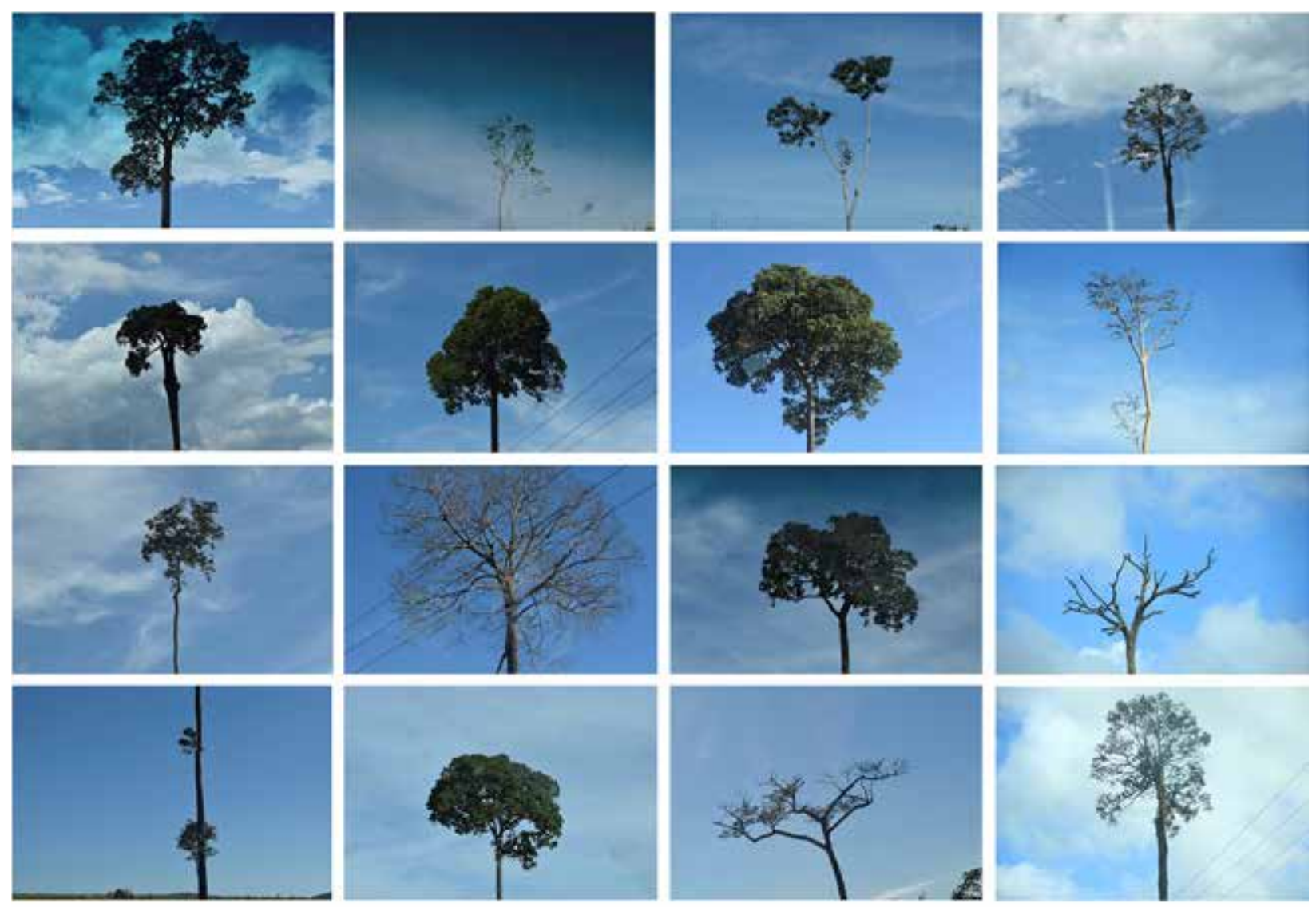

Figura 6 - Uma coleção de castanheiras possíveis.

Cinthya Marques. 2016, PA.

mais rápidos diante de outras -, não existiria para nós nada "duradouro", mas tudo se desenrolaria diante de nossos olhos, tudo viria de encontro a nós. Ora, é exatamente isso que se passa com o grande colecionador em relação as coisas. Elas vão de encontro a ele. Como ele as persegue e as encontra, e que tipo de modificação é provocada no conjunto das peças por uma nova peça que se acrescenta, tudo isto lhe mostra suas coisas em um fluxo contínuo. (P. 239-240)

Solitárias e grandiosas, ao colecionar estas imagens construo uma coleção que passa pela operação artística do registro fotográfico através da linguagem digital, para posteriormente realizar a seleção e organização das imagens produzidas, em prol de pensar as fotografias das árvores castanheiras enquanto memórias colecionáveis, e discutir essa coleção.

Porém, cabe pensar nessas imagens enquanto retratos que se afirmam na paisagem e que demonstram, segundo Jacques Rancière que as imagens da arte são operações que produzem uma distância, uma dessemelhança (p. 15, 2003)
Cabe retomar o conceito de Arquissemelhança de Jacques Rancière, porque para a produção do trabalho expositivo as imagens são alinhadas por tons de azul e branco do céu; pelas dimensões dos galhos e troncos de árvores, buscando nessas representações, relações, percursos visuais que aproximem as fotografias sejam pela similitude ou dissemelhança:

"A imagem daarte separa suas operações da técnica
que produz semelhanças. Todavia, reencontra
em seu caminho outra semelhança, a que define
a relação de um ser com sua proveniência e sua
destinação, a que dispensa o espelho favorecendo
a relação imediata do genitor com o engendrado:
visão face a face, corpo glorioso da comunidade
ou marca da própria coisa. Chamemos isso de
arquisemelhança. Ela é a semelhança originária,
a semelhança que não fornece a réplica de uma
realidade, mas o testemunho imediato de um outro
lugar, de onde ela provém. Essa arquissemelhança
é a alteridade que nossos contemporâneos
reinvindicam para a imagem ou deploram que se
tenha esvaído junto com ela." (RANCIĖRE, p.17) Diante disto então considero que a coleção é um registro vivo da história e da vida das 
árvores castanheiras que resistem no tempo e na paisagem, pois apesar de sua condição solitárias, as castanheiras permanecem nesta região em menor escala do que fora outrora, quando explorada durante o ciclo da castanha na Amazônia. Para a construção de uma coleção de castanheiras possíveis é preciso ter consciência que se trata de uma árvore que sempre pertecerá à sua natureza, solitária e grandiosa e que está coleção está na produção das imagens e memória.

Por isso muitos registros fotograficos das castanheiras passam pela dúvida de reconhecimento dessas árvores - porque aqui não se trata de uma pesquisa em biologia, mesmo que a Botânica possa auxiliar nos estudos do campos da Arte.

Trata-se de uma pesquisa de auto-reconhecimento desta história da Amazônia pouco contada, que não foi documentada da forma que deveria, e que mesmo presente no imaginário coletivo pouco sabe-se sobre as condições que estas árvores estão inseridas na paisagem contemporânea. Para refletir sobre essa temática é que a coleção existe de modo que as árvores que a compõem sejam lembradas exatamente na paisagem em que foram encontradas e reconhecidas como símbolo de resistência, seja pela grandiosidade de suas raízes e troncos ou pela existência que insiste em permanecer nos campos abertos da paisagem amazônica e na memória da região que tem essas árvores como símbolo e identidade.

\section{NOTAS}

1. Fotografei a experiência utilizando a linguagem digital e analógica - esta que posteriormente se revelaria uma grata surpresa ao descobri as sobreposições acidentais de dois lugares que visitei no período: a região sul do Pará e a periferia da capital do estado, Belém. Assim surge a série "Dois mundos à espera", que relaciona as paisagens distantes do mesmo estado.

2. Capítulo Alteridade das imagens, do livro: 0 destino das imagens (Rio de Janeiro, 2012). Pg. 14.

3. Capítulo Imagem, semelhança, arquissemeIhança, do livro: O destino das imagens (Rio de Janeiro, 2012). Pg. 17.

\section{REFERENCIAS}

BARON, Dan. Alfabetização cultural - a luta íntima por uma nova humanidade. São Paulo: Alfarrabio, 2004.

BENJAMIN, Walter. Passagens. São Paulo: Imprensa Oficial, 2007.

RANCIÈRE, Jacques. 0 destino das imagens. Rio de Janeiro: Contraponto, 2003.

\section{SOBRE A AUTORA}

Cinthya Marques Do Nascimento é docente e pesquisadora da Universidade Federal do Sul e Sudeste do Pará - UNIFESSPA, atua na direção e coordenação da Faculdade de Artes Visuais (Fav/ Unifesspa). É mestre (Msc) em Artes pelo Programa de Pós-Graduação em Artes - PPGARTES da Universidade Federal do Pará - UFPA, com ênfase na linha de pesquisa Processos de Criação e Atuação em Artes. Desenvolve projetos artísticos enquanto artista visual e fotógrafa, com ênfase na criação de narrativas visuais. Seus projetos discutem as noções de pertencimento relacionados ao ser andarilho e estar estrangeiro. Reside em Marabá (PA) desde 2017. 